\title{
¿Afecta la corrupción y su investigación policial a los objetivos del desarrollo sostenible?
}

\author{
Martín Sánchez Sánchez
}

Recibido: 14/12/2020 / Aceptado: 08/07/2021

\begin{abstract}
Resumen. La corrupción es una acción humana que puede darse en cualquier contexto en el que un ciudadano pueda participar y debe de observarse desde un punto de vista amplio, no estanco, puesto que suele interrelacionarse con otras actividades delictivas. La existencia de corrupción detrae recursos estatales, supone una grave amenaza para la estabilidad político-social y merma la credibilidad del estado frente al ciudadano, dificultando además la eficacia de las estrategias nacionales planeadas para alcanzar los Objetivos de Desarrollo Sostenible. Así pues, la investigación policial en torno a la corrupción y sus delitos conexos resulta primordial para el Estado y para la ciudadanía, permitiendo un desarrollo económico, medioambiental y social, seguro y sostenible, en el marco de los objetivos planteados en la Agenda 2030.
\end{abstract}

Palabras clave: Corrupción, PIB, blanqueo de capitales, crimen organizado, alarma social, especialización, formación, internacional.

\section{[en] Does corruption and its investigation by the police affect sustainable development goals?}

Summary. Corruption is a human action that can occur in any context in which a citizen may be involved and must be viewed from a broad, not a narrow, perspective, as it is often interrelated with other criminal activities. The existence of corruption detracts from state resources, poses a serious threat to political and social stability and undermines the credibility of the state in the eyes of citizens, as well as hindering the effectiveness of planned national strategies to achieve the Sustainable Development Goals. Therefore, the police investigation of corruption and related crimes is essential for the state and for citizens, enabling secure and sustainable economic, environmental and social development, within the framework of the goals set out in the 2030 Agenda.

Keywords: Corruption, GDP, money laundering, organised crime, social alarm, specialisation, training, international.

Sumario. 1. Introducción, 2. Definición de corrupción, 3. El coste de la corrupción, 4. ¿Cómo se enfrenta la Policía a esta problemática delictiva?, 4.1. Investigaciones complejas, 4.2. Investigaciones que requieren especialización, 4.3. Investigaciones que requieren formación, 4.4. La vertiente internacional, Conclusiones. Bibliografía.

Cómo citar: Sánchez Sánchez, M. (2021): ¿Afecta la corrupción y su investigación policial a los objetivos del desarrollo sostenible?, en Cuadernos de Gobierno y Administración Pública 8-1, 91-104.

\section{Introducción}

Resulta imposible establecer un punto de partida, una fecha o acontecimiento histórico a partir del cual puede hablarse del nacimiento de la corrupción, es una actividad propia del ser humano y de su organización social que "transgrede las normas legales y los principios éticos" (López González, 2018) del momento histórico en el que se encuentre y tratándose de una acción humana, puede por tanto darse en cualquier contexto en el que participe: social, laboral, deportivo, penal, administrativo, político...

La corrupción, "entendida como abuso de poder público para obtener una ventaja ilegítima en beneficio privado ha sido una constante a lo largo de todas las sociedades para obtener decisiones favorables de quienes ostentan el poder" (Rasillo, 2016); este beneficio privado al que se hace referencia podría tener distintas formas, patrimonial o de otro tipo, pero generalmente siempre tendrá su conversión, de alguna manera, en beneficio económico.

Numerosos ejemplos de corrupción nos aporta la historia de la humanidad: en el México precolombino se castigaba con la muerte la corrupción llevada a cabo por los recaudadores de impuestos que cobraban más de lo debido con el objeto de enriquecerse; en Egipto, en la época del Reino Nuevo (1550 a.C. - 1070 a. C.)

\footnotetext{
Inspector-Jefe de la Policía Nacional, Jefe de la Unidad Adscrita de Policía Judicial del Cuerpo Nacional de Policía a la Fiscalía Especial contra la Corrupción y la Criminalidad Organizada. E-mail: msanchez0210@policia.es
} 
también había corrupción, de hecho se ha encontrado documentación en la tumba del emperador Ramsés IX que informa de hechos vinculados a la corrupción de funcionarios públicos; e incluso en la Grecia clásica, en la figura de Demóstenes, que en el siglo IV a. C., según el relato atribuido al filósofo griego Cristolao, "Historia de los embajadores de Mileto y del orador Demóstenes", habría recibido dinero de unos diplomáticos procedentes de la ciudad de Mileto a cambio de que no hablara negativamente de los milesios.

Pero la corrupción no puede observarse desde un punto de vista estanco, por su propia naturaleza, no es un hecho o una actividad que se base en acciones delictivas puntuales, únicas o independientes, puesto que de manera habitual la corrupción está íntimamente relacionada con la delincuencia económica en general y con el crimen organizado en particular.

La propia naturaleza de la corrupción y de las conductas criminales afines a la misma la convierten en una de las principales barreras que se anteponen en la consecución de los objetivos y metas adoptados por la ONU para el año 2030 desde una triple perspectiva:

1. La corrupción provoca falta de eficacia en las estrategias nacionales para alcanzar los Objetivos de Desarrollo Sostenible.

2. La corrupción induce a la falta de recursos destinados a los Objetivos de Desarrollo Sostenible, circunstancia directamente relacionada con la redistribución de los ingresos del Estado, es decir, con la actividad presupuestaria del Gobierno, la cual se vería contrarrestada de manera significativa.

3. La corrupción evita la consolidación de la democracia, amenaza la estabilidad política y conlleva a que el ciudadano pierda credibilidad en el gobierno y en las instituciones públicas, lo que supone que los Objetivos y metas marcadas por la ONU para un Desarrollo Sostenible sean vistas por la sociedad desde la distancia y sin una verdadera implicación, constituyéndose como una auténtica utopía.

\section{Definición de corrupción}

Encontrar un concepto unívoco de corrupción no resulta sencillo, cabe señalar a modo de ejemplo, que ni si quiera en la Resolución 58/14 de la Asamblea General de la ONU, de 31 de octubre de 2003, por la que se aprueba la Convención de las Naciones Unidas contra la Corrupción, se incluye una definición de corrupción, aportando un listado de conductas que los Estados deberán tipificar como delito por entender que se encuentran incluidos en el concepto de corrupción, formaría parte de esta lista delitos como el cohecho, la extorsión, la malversación, la apropiación indebida, el tráfico de influencias, el abuso de funciones o el enriquecimiento ilícito entre otros.

Puede observarse como característica común a todos los comportamientos citados anteriormente la "desviación de un poder de actuación en un interés particular para la consecución de una ventaja indebida, patrimonial o de otro tipo, en su favor o en la de otro" (Rasillo 2015), ya sea pública o privada.

Cabe destacar que España firmó la Convención de las Naciones Unidas contra la Corrupción el 16 de septiembre de 2005, ratificándola el 19 de junio de 2006; por su parte, no fue hasta el año 2008, con la Decisión del Consejo 2008/801/CE, cuando se autorizó a la Unión Europea a firmar la Convención, es decir, no ha sido hasta el siglo XXI cuando los Estados han comenzado a tomar conciencia de la importancia del fenómeno de la corrupción y de su relación con otras actividades criminales, a pesar de que, como ya hemos señalado, la corrupción ha ido de la mano del ser humano desde las primeras civilizaciones.

Esta creciente preocupación de carácter mundial respecto a la corrupción se ha visto reflejada en nuestra legislación penal, fundamentalmente en el último decenio, en el que se han llevado a cabo varias modificaciones en el Código Penal vinculadas estrechamente a la corrupción y a las actividades delictivas que se relacionan directamente con ella y es que en nuestra legislación existe un amplio abanico de tipos penales que de alguna manera estarían relacionados con la corrupción y que ayudarían a definirla y a identificarla, estos tipos penales a los que nos referimos son, fundamentalmente y como mínimo, los encuadrados en los siguientes Títulos del Código Penal:

- Título XIII: la extorsión, la usurpación, las defraudaciones, la frustración de la ejecución, las insolvencias punibles, la alteración de precios en concursos y subastas, delito de daños, delitos relativos a la propiedad intelectual e industrial, al mercado y a los consumidores, delitos societarios y delitos de receptación y blanqueo de capitales.

- Título XIII bis, por definición: de los delitos de financiación ilegal de los partidos políticos.

- Títulos XIV, XV, XV bis y XVI, respectivamente: de los delitos contra la Hacienda Pública y contra la Seguridad Social, de los delitos contra los derechos de los trabajadores, de los delitos contra los derechos de los ciudadanos extranjeros, de los delitos relativos a la ordenación del territorio y el urbanismo, la protección del patrimonio histórico y el medio ambiente.

- Título XVIII: de las falsedades.

- Título XIX: delitos contra la administración pública.

Por tanto, a pesar de no poder especificar de una manera clara y concisa qué es la corrupción desde un punto de vista penal, resulta evidente que la persecución de este delitos y de los estrechamente relacionados con la misma resulta absolutamente necesario y prioritario, puesto que incidirá directa e inmediatamente en la percepción que la comunidad tiene de las instituciones sociales, y permitirá al Estado contar con mayores recursos para cumplir con sus obligaciones en lo relativo al problema de la distribución del gasto, fundamental a la hora de afrontar los objetivos y metas adoptados por la ONU para el 2030. 


\section{El coste de la corrupción}

Por pura lógica, no existen cifras oficiales de contabilidad nacional que certifiquen el coste de la corrupción $\mathrm{y}$ de los delitos vinculados directamente a la misma en Estado alguno, sin embargo, si pueden encontrarse estimaciones macroeconómicas que tratan de establecer cierta relación entre estas actividades delictivas y sus efectos sobre la economía nacional de un país o sobre una pluralidad de estados.

A la hora de estimar cantidades nos centraremos en los beneficios obtenidos directamente por la corrupción, pero no podemos dejar a un lado su relación, ya sea directa o indirecta, con el crimen organizado y con el fraude fiscal, teniendo como elemento trasversal a todos ellos, el blanqueo de capitales.

Utilizaremos para el cálculo lo señalado por el profesor alemán Friedrich Schenider ${ }^{2}$ quién cifró el importe de la corrupción en los países de la OCDE en torno al $1 \%$ de su PIB, de hecho, la Comisión Europea calculó en el año 2014 que la corrupción costaba aproximadamente 120.000 millones de euros anuales a la Unión Europea, lo que equivaldría exactamente al 1\% del PIB de la Unión en aquel año. Este 1\%, a precios del año 2019, serían aproximadamente 12.500 millones de euros en España ${ }^{3}$.

Pero son numerosos los estudios los que elevan considerablemente esta cuantía para España, ya en el año 2013 la Universidad de Las Palmas cifró el coste de la corrupción en más de 40.000 millones de euros al tomar en cuenta su coste social sobre la calidad de vida y su efecto negativo en la inversión extranjera.

En el mismo sentido, en el año 2015, la Comisión Nacional de los Mercados y la Competencia estimó que la falta de competencia derivada de la corrupción generaría un sobrecoste equivalente al $4,5 \%$ del PIB, que a precios del año 2019 rondaría los 56.000 millones de euros.

En el año 2018, el Grupo de los Verdes/Alianza Libre Europea, constituido por 52 eurodiputados publicó el estudio "The cost of corruption across EU" sobre el impacto social de la corrupción en la Unión Europea, estimando que en España costaría unos 90.000 millones de euros, casi el 7,5\% del PIB.

Si a estos importes le sumamos el impacto que en la economía nacional tiene el crimen organizado y el fraude fiscal, nos encontramos ante una situación de difícil solución, no solo para poder dar una respuesta adecuada a los objetivos y metas adoptados por la ONU para el 2030, sino también para la propia subsistencia de nuestro país, valga como ejemplo que la $\operatorname{UNDOC}^{4}$ (Oficina de las Naciones Unidas para el Delitos y el Tráfico de Drogas) estimó en su informe anual para el año 2014

Catedrático de la Universidad Johannes Kepler de Linz (Austria), autor de numerosos informes y estudios relacionados con la economía sumergida y la corrupción.

3 Según datos del Instituto Nacional de Estadística, en el año 2019 el PIB a precios corrientes de España se sitúa en 1.244.757 millones de euros; para facilitar los cálculos realizados en este artículo el autor ha redondeado la cifra y para referirse al PIB español del año 2019 ha utilizado la cantidad de 1.250.000 millones de euros.

United Nations Office on Drugs and Crime. que los beneficios que obtenía el crimen organizado a nivel mundial eran aproximadamente de unos 870.000 millones de dólares USA, aproximadamente $2 \%$ del PIB mundial. Esta circunstancia, trasladada a la economía española se traduciría en aproximadamente $25.000 \mathrm{mi}-$ llones de euros del año 2019.

Por lo que respecta al fraude fiscal, en virtud del informe emitido en junio de 2017 por el Consejo General de Economistas, este fenómeno generaría en España pérdidas que equivalen aproximadamente al 2,5\% del PIB nacional, es decir, unos 31.000 millones de euros. Todo esto sin entrar a valorar otras cuestiones del mismo estudio en el que se estimaba que la economía sumergida en España rondaría una cantidad cercana al 16\% del PIB nacional, es decir unos 200.000 millones de euros.

El vértice común de los delitos señalados anteriormente es el blanqueo de capitales, que se constituye como un elemento transversal a la corrupción, al crimen organizado y al fraude fiscal, ya que su fin último es el de introducir en la economía real los beneficios obtenidos de la realización de actividades ilícitas, simulando una procedencia legal.

Así pues y a modo de glosario, el coste estimado sobre el PIB español de la corrupción estaría entre los 12.500 millones de euros (1\% del PIB) y los $90.000 \mathrm{mi}-$ llones de euros (7,5\% del PIB); si a esto le sumamos el coste del crimen organizado, unos 25.000 millones de euros (2\% del PIB) y el del fraude fiscal, unos 31.000 millones de euros (2,5\% del PIB), obtendríamos una cantidad cercana a los $110.000^{5}$ millones de euros, es decir, casi el 9\% del PIB nacional.

Las cifras anteriormente señaladas son inasumibles desde cualquier punto de vista y para cualquier Estado, pero la situación se complica aún más cuando las comparamos con el presupuesto de 8.879 millones de euros, un $0,7 \%$ del PIB, que el Gobierno de España ha asignado al Ministerio del Interior para el año 2019 y con los 1.869 millones de euros, un $0,15 \%$ del PIB, asignados al Ministerio de Justicia. Incluso, poniendo el punto de mira de manera exclusiva en la corrupción, sin actividades asociadas, podemos observar que su coste, 12.500 millones de euros, es muy superior a la suma de los presupuestos de los dos ministerios protagonistas en la lucha contra la misma.

Se puede afirmar por tanto que la actividad delincuencial en general y que la corrupción en concreto, son un buen negocio para el delincuente y que los instrumentos básicos con los que cuenta el Estado para combatirla, a través del Ministerio del Interior y del Ministerio de Justicia, no alcanzan presupuestariamente, en volumen, al supuesto beneficio que consigue el corrupto con su deleznable actividad.

Así pues, la influencia de estas actividades delictivas en el presupuesto estatal no es algo trivial, todo lo contrario, resulta del todo significativo, y esta importancia se convierte en un factor determinante si tenemos en cuenta el compromiso adquirido en el cumplimiento de

Para hacer el cálculo se ha hallado la media entre los 12.500 millones de euros del 1\% de Schenider y los 90.000 millones, por ser la cifra más alta, del estudio del año 2018. 
los Objetivos de Desarrollo Sostenible contenido en la Agenda 2030, más aún si nos centramos en las acciones llevadas a cabo desde el sector público, que se ven reducidas inexorablemente por el peso económico de las actividades delictivas descritas anteriormente.

A la circunstancia anterior hay que sumarle que los recursos que se dedican al cumplimiento de los Objetivos de Desarrollo Sostenible en España aún no cuentan con un sistema de clasificación y seguimiento que nos permita medirlos correctamente. Es cierto que el esfuerzo presupuestario que en esta materia están realizando las administraciones públicas es creciente, pero todavía se carece de un sistema que, por ejemplo, permita incorporar una metodología que facilite la realización de comparaciones entre las distintas comunidades autónomas.

\section{4. ¿Cómo se enfrente la policía a esta tipología delictiva?}

Como hemos visto, en base a los argumentos anteriormente expuestos, la investigación policial en torno a la corrupción y al conjunto de delitos con los que se relaciona se convierte en una herramienta fundamental para el Estado y por ende para la ciudadanía, entre otros motivos porque impediría, al menos en parte, la desviación de estas enormes cantidades de dinero a las que se ha hecho referencia anteriormente y facilitaría la aprehensión de los frutos del delito, sea cual fuere su formato (dinero en efectivo, en cuentas bancarias o transformado en cualquier inmovilizado material), para devolver al Estado y que éste pudiera redistribuirlo eficazmente.

A la hora de afrontar cualquier investigación relacionada con la corrupción, quienes ostentan la dirección de los servicios policiales saben que los investigadores tendrán que enfrentarse situaciones complejas que requieren especialización de los funcionarios actuantes, funcionarios policiales que deberán de tener un mínimo de experiencia y suficiente formación para poder afrontarlas con cierta garantía, sin olvidar que en estas investigaciones suele existir una vertiente internacional, cada vez más destacada, y que por tanto no debe de ser olvidada.

\subsection{Investigaciones complejas}

Cualquier investigación relacionada con la corrupción es compleja debido a, entre otros, los siguientes condicionantes:

1. En la mayoría de las investigaciones por corrupción no entra en juego un único tipo delictivo, sino que en torno a la corrupción hay numerosos tipos penales que pueden intervenir y no solo ellos, también los vinculados al crimen organizado, al fraude fiscal y a la materia trasversal de todos ellos, el blanqueo de capitales.

2. ${ }^{\circ}$ El objeto de la investigación es extremadamente amplio puesto que se investigará:

a. La utilización de potestades públicas para un interés privado, o lo que es lo mismo, el abuso de una posición de control público para obtener beneficios privados, circunstancia muy difícil de demostrar sin determinados medios técnicos, sin la realización de investigaciones patrimoniales y sin la colaboración de arrepentidos o testigos de los hechos.

Es importante señalar que estas actividades ilegales desarrolladas por el funcionario público o por la administración en general, en muchas ocasiones, ha salvado auditorías internas o incluso ha contado con la participación de las mismas.

En relación con las actividades ilegales que pudiera llevar a cabo un funcionario público cabe recordar el Objetivo número 16 de Desarrollo Sostenible: "Promover sociedades pacíficas e inclusivas para el desarrollo sostenible, facilitar el acceso a la justicia para todos y construir a todos los niveles instituciones eficaces e inclusivas que rindan cuentas", destacando que en España, el porcentaje de las personas que han tenido por lo menos un contacto con un funcionario público, pagaron un soborno a un funcionario público, o tuvieron la experiencia de que un funcionario público les pidiera que lo pagaran es de tan solo el $0,0003 \%{ }^{6}$, cifra ínfima que, como veremos más adelante, se enfrenta a los resultados obtenidos por España en el Índice de Percepción de la Corrupción elaborado por Transparencia Internacional.

b. La corrupción privada, también denominada corrupción entre particulares, que tuvo su entrada en nuestro Código Penal en el año 2010 y que en el año 2015, con la Ley Orgánica 1/2015 se contempló de una manera más amplia, castigando al directivo, administrador, empleado o colaborador de cualquier empresa que reciba, solicite o acepte un beneficio o ventaja a cambio de favorecer a otro en las relaciones comerciales, y al contrario, prometer, ofrecer o conceder un beneficio o ventaja como contraprestación, para lograr un trato de favor indebido frente a otros en las relaciones comerciales.

Regulando esta actividad se pretende proteger el buen funcionamiento del mercado, tratando de impedir que se lleven a cabo determinas acciones, muy arraigadas en las relaciones empresariales, que favorecían posiciones de ventaja en las relaciones económicas y que influían sobre la justa y honesta competencia. Estas actividades son muy difíciles de investigar puesto que en pocas ocasiones son auditadas y aún a día de hoy se siguen asumiendo como propias de la habilidad comercial o empresarial, como una forma habitual de hacer negocio. 
En este ámbito de la corrupción privada nos encontraríamos también con la predeterminación o alteración de una competición deportiva de especial relevancia; en la mayoría de las ocasiones se conoce que existe corrupción en una competición deportiva una vez ha sido corrompida, por lo que los medios disponibles para probarla son muy escasos.

c. El conjunto de bienes y derechos propios de una persona (física o jurídica) susceptibles de estimación económica, es decir, el patrimonio, que en la mayoría de las ocasiones quiere permanecer oculto, a nombre de terceros, vinculado directa o indirectamente con los investigados, en España o en extranjero y también a través de contratos fiduciarios.

d. El enriquecimiento ilícito experimentado por el investigado que carece de medios económicos que sustenten su enriquecimiento personal o societario declarado y reconocido, que el investigado trata de justificar fraudulentamente y que podría relacionarse con actividades delictivas, incluyendo, por ejemplo, el abuso en la función pública.

Estas circunstancias definen en gran parte la tipología penal del blanqueo de capitales, suponiendo en ocasiones una complejidad extrema el tener que demostrar que efectivamente el enriquecimiento tiene naturaleza ilegal.

Cabe recordar que en España no existe el delito de enriquecimiento ilícito, aunque el enriquecimiento injustificado se haya utilizado como indicio para acreditar el blanqueo de capitales, no existe esta figura penal en España, a pesar que en el artículo 20 de la Convención de las Naciones Unidas contra la Corrupción se aconseja su tipificación.

e. Actividades económicas en general para llevar a cabo determinadas afirmaciones relacionadas con el patrimonio real de una persona física o jurídica. Hay que analizar numerosas y diferentes actividades económicas utilizadas por los investigados que dificultarán la labor investigativa, actividades vinculadas al campo empresarial, comercial, financiero, bancario, crediticio, bursátil, hipotecario, tributario, contable, etc.

f. Actividades urbanísticas: investigar actividades urbanísticas, vinculadas a la ordenación del territorio y/o del medio ambiente; encierra tal complejidad que en muchas ocasiones ni siquiera los profesionales encargados de controlar estas actividades ( $\mathrm{IGAE}^{7}$, arquitectos municipales, auditores,...) identifican las posibles irregularidades que pudieran estar llevándose a cabo.

En relación con las actividades ilegales que pudiera llevar a cabo en relación con el urba-

Intervención General de la Administración del Estado. nismo cabe recordar el Objetivo número 15 de Desarrollo Sostenible: "Proteger, restablecer y promover el uso sostenible de los ecosistemas terrestres, gestionar sosteniblemente los bosques, luchar contra la desertificación, detener e invertir la degradación de las tierras y detener la pérdida de biodiversidad" y en este sentido, en España, sobre todo en el último cuarto del siglo XX y primeros del XXI, la deriva urbanística se antepuso a la protección de la vida de los ecosistemas terrestres, aun así y contrariamente a lo esperado, la superficie de bosque en proporción a la superficie total es del $36,47 \% \%^{8}$, otro cosa bien distinta es si entramos en el ámbito de la urbanización de la costa española puesto que estaría construida el 13\% de la misma frente al $2 \%$ del interior del territorio nacional, encontrándonos con que el $80 \%$ de los recursos ambientales de la costa estarían degradados tras 30 años de urbanización masiva ${ }^{9}$.

A precios del año 2017 los presupuestos del estado destinaron algo más de 2 millones de euros ${ }^{10}$ para la conservación y el uso sostenible de la diversidad biológica y de los ecosistemas, importe que vista la información plasmada anteriormente parece del todo insuficiente.

g. Documentos falsificados o manipulados que tienen por objeto engañar a personas con tienen formación, especializadas y técnicas, como pueden ser asesores fiscales, laborales, empleados de sucursales bancarias, abogados o incluso notarios que, muy a su pesar, sucumben ante estos documentos hábilmente elaborados o modificados.

h. Y por supuesto también actividades delictivas relacionadas con la delincuencia tradicional y con el crimen organizado.

3. La persona física o jurídica que se investiga.

En los delitos relacionados directa o indirectamente con la corrupción existen diferentes personas físicas o jurídicas que pueden ser de interés para los hechos investigados y que suponen una complejidad añadida ante los mismos:

a. En muchas ocasiones es una persona física la presunta autora de los hechos investigados, encerrando así las mismas complicaciones que en cualquier otro delito investigado por la policía.

b. En otras ocasiones el interés de la investigación recae en una persona jurídica, cualquiera que sea su denominación legal, responsable también penalmente, pero con, por su propia naturaleza, características que le aportan una mayor opacidad.

\footnotetext{
Fuente: Instituto Nacional de Estadística.

Fuente: Informe "A Toda Costa", elaborado por Greenpace y el Observatorio de la Sostenibilidad fechado el 24-07-2018.

10 Fuente: Instituto Nacional de Estadística.
} 
c. Ya sea una persona jurídica la investigada o una persona física, en gran parte de los casos se trata de personalidades interpuestas, testaferros u hombres de paja que tratan de ocultar la verdadera identidad del responsable real de los hechos investigados.

d. A veces los investigados son empresarios con trabajadores contratados, los cuales dependen económicamente, de una manera directa, de la suerte que corra este empresario; en otras ocasiones estos mismos empresarios son conocidos por la opinión pública y todas estas circunstancias acumulan dificultades en el desarrollo de la investigación.

e. También se investigan empresas públicas, con todas las dificultades que conlleva, fundamentalmente en lo que se refiere a la recopilación de información y a la filtración de la misma.

f. En determinadas operaciones se investigan primeramente sucursales bancarias para después determinar que empleados y/o responsables de la misma serían objeto de investigación.

g. Otros objetos de investigación pueden ser las asesorías jurídicas, laborales, financieras, puesto que en ocasiones pueden extralimitarse en su "asesoramiento" y colaborar activamente en la comisión de un hecho delictivo.

h. Las Corredurías de seguros, por las mismas razones expuestas anteriormente y también, porque pueden haber sido utilizadas para dificultar el seguimiento del dinero o de la actividad criminal, pueden ser objeto de investigación.

i. Notarías, dado el importante papel de intermediario que realizan en muchos de los negocios jurídicos que se investigan y dada su responsabilidad en la comunicación a las autoridades pertinentes respecto de determinadas actividades sospechosas vinculadas al blanqueo de capitales o la financiación del terrorismo.

j. Despachos de abogados: gracias a la actividad que desarrollan, pueden realizar "asesoramientos" relacionados con actividades criminales, pueden facilitar herramientas para dificultar el seguimiento del dinero, pueden participar como intermediarios en diferentes negocios jurídicos y además tienen también la obligación de comunicar aquellas operaciones que pudieran estar vinculadas con el blanqueo de capitales.

k. También pueden ser objeto de investigaciones relacionadas con la corrupción personas conocidas públicamente como artistas, deportistas de élite o clubes de fútbol como personas jurídicas.

1. Otras figuras especialmente complejas de investigar en el mundo de la corrupción son los partidos políticos o los sindicatos y los miembros de ambos conocidos como $\mathrm{PEP}^{11}$ que en

1 Politically Exposed People. muchas ocasiones ejercen laborales de representación pública o institucional.

m. Y finalmente, como no podía ser de otra manera, también son objeto de investigación las organizaciones criminales y sus miembros.

4. ${ }^{\circ}$ La alarma social generada.

Los delitos relacionados con la corrupción, también denominados de forma genérica de cuello blanco o como los etiquetó Edwin H. Sutherland en 1949, "White Collar Crime", parecían en un principio soportar un menor reproche social y penal que el resto de actividades delictivas, sin embargo, esta situación ha ido cambiado, se ha evidenciado una evolución vinculada a una mayor conciencia social respecto de "lo público", de lo que es "de todos", en gran medida porque el ciudadano ha sufrido en primera persona los recortes sociales de crisis precedentes logrando que esa transigencia inicial de la que gozaban muchos de los corruptos se ha ido transformando en una claro reproche social y consecuentemente penal.

El ciudadano espera una respuesta rápida y contundente por parte del Estado a través de las Fuerzas y Cuerpos de Seguridad del Estado, de ahí que esta alarma social tome forma en una mayor presión sobre la investigación, fundamentalmente a través de los medios de comunicación.

La alarma social que generan los delitos relacionados con la corrupción y el blanqueo de capitales es innegable, por un lado, la corrupción genera desconfianza entre la ciudadanía, además del hecho de lastrar el desarrollo, ya no digamos su sostenibilidad, desalentar la inversión extranjera y detraer recursos públicos que podrían ser empleados por el Estado en la satisfacción de otras necesidades y prioridades de la población. Por el otro lado, el blanqueo de capitales forma parte de la delincuencia organizada y ha favorecido la aparición de nuevas formas de delitos que también han provocado gran repercusión y alarma social, llegando a contribuir de forma evidente a la desestabilización de los sistemas económicos. Evidentemente, medir la alarma social resulta un ejercicio muy complicado ya que se trata de un término abstracto que lleva aparejado un alto porcentaje de subjetividad, de hecho, la alarma social es un elemento que no controla el sujeto al que se acusa de causarla, en realidad es desplegada por el que la difunde, dándole la fuerza que la propagación mediática le otorga. En otras palabras, la alarma social es causada por la difusión de un hecho y sus efectos se vuelcan sobre el individuo que la ha realizado, aunque jamás haya tenido intención de la más mínima repercusión social. Por tanto, medir la alarma social generada por un determinado hecho criminal resulta una tarea casi imposible.

A pesar de lo expuesto anteriormente, existe una herramienta utilizada con carácter general que ayuda a visualizar qué percepción tiene la 
ciudadanía de un país en concreto respecto a la corrupción en el mismo. Se trata del Índice de Percepción de la Corrupción (IPC) de la organización no gubernamental Transparencia Internacional, la cual "tiene por objeto combatir la corrupción, congregando a la sociedad civil, al sector privado y a los gobiernos en una amplia coalición global ${ }^{12}$ ".

La organización no gubernamental Transparencia Internacional publica desde 1995 el índice de percepción de la corrupción que mide, en una escala de cero (percepción de muy corrupto) a cien (percepción de ausencia de corrupción), los niveles de percepción de corrupción en el sector público en un país determinado y que consiste en un índice compuesto, que se basa en 13 encuestas y evaluaciones elaboradas por expertos que luego se unifican en una sola puntuación.

Según Transparencia Internacional, los resultados del IPC del año 2019 señalan que la corrupción sigue siendo un fenómeno mundial de carácter general y contempla la percepción de corrupción en el sector público en 180 países, de los cuales, más de dos tercios obtuvieron una puntuación inferior a 50 puntos.

Dinamarca y Nueva Zelanda son los países que ocupan el primer lugar desde hace ya varios años consecutivos, mientras que Somalia y Sudán del Sur muestran los peores resultados.

Los países en las primeras posiciones presentan características comunes que son clave: altos niveles de libertad de prensa; acceso a información sobre presupuestos que permite al público saber de dónde procede el dinero y cómo se gasta; altos niveles de integridad entre quienes ocupan cargos públicos; y un poder judicial que no distingue entre ricos y pobres, y que es verdaderamente independiente de otros sectores del gobierno.

En lo que concierne exclusivamente a España, destacar que ha mejorado sensiblemente en los últimos años, ocupando la posición 30 de entre los 180 países y el 13 de entre los 27 de la $\mathrm{UE}^{13}$, poniendo de manifiesto que aunque en España sigue siendo un problema grave la corrupción, ésta no es sistémica y en gran parte, la explicación de este índice tan elevado en relación con los países de nuestro entorno se debe a:

- Los sistemas de control se han mostrado eficaces y han logrado aflorar numerosos casos de corrupción

- Las denuncias de los medios de comunicación y la relevante atención prestada a los casos aflorados han influido intensamente en la percepción ciudadana, generando un estado general de indignación.

2 En: http://transparencia.org.es/

13 Cabe recordar que entre 2012 y 2018, la calificación de España cayó en 7 puntos, siendo el país que más había caído en puntuación en Europa y, por ello, donde más subió la percepción.
- Las últimas crisis económicas sufridas han incrementado el nivel de exigencia social.

Aunque el enfriamiento de la economía, especialmente en el sector urbanístico, permite pensar que los casos de corrupción se han reducido en ese ámbito, la lentitud de las sanciones penales, la baja intensidad de las penas en casos de corrupción relevante, la expansión de los escándalos a las instituciones clave del Estado y la sensación de impunidad, explican la percepción social negativa que se mantiene en este Índice.

Para continuar en su mejora, según Transparencia Internacional, España debería de garantizar la integridad política y el buen funcionamiento de las instituciones públicas y tener una estrategia holística de prevención y lucha contra la corrupción con mecanismos que permitan poner de manifiesto cuales son las causas concretas que en España han dado lugar a los escándalos de corrupción en democracia.

5. Otras de las razones que ponen de manifiesto la complejidad de este tipo de investigaciones es la dificultad o imposibilidad de obtener pruebas directas inculpatorias en la corrupción y el blanqueo de capitales, de hecho, el Tribunal Supremo, en numerosas sentencias, señala el delito de blanqueo de capitales como un delito asentado en la prueba indiciaria, siendo los tres pilares básicos que lo acreditan:

a. Incremento inusual de patrimonio.

b. Inexistencia de negocios lícitos que justifiquen el incremento patrimonial.

c. Vinculación con actividades delictivas.

El delito de blanqueo es un tipo independiente a la preexistencia de otros delitos que den origen al patrimonio. No requiere de una prueba directa, sino indiciaria, también llamada circunstancial o de presunciones, necesitando como elemento subjetivo solo el "conocimiento del origen ilícito" de los bienes que luego se introducen en la economía legal, sin embargo, ese conocimiento del origen ilícito que podrían inducir a pensar que facilita la investigación, en ocasiones se muestra como una frontera infranqueable, como una dificultada añadida, como puede ser el caso del blanqueo de capitales en España cuyo origen son actos de corrupción en un país corrupto que negará ese origen ilícito.

Por lo tanto, la investigación patrimonial tiene una especial trascendencia como parte de la investigación en sí, no solo para intervenir bienes y activos, sino también como medio para esclarecer el delito. Es fundamental averiguar el patrimonio del que es titular el investigado o aquel que se le pueda atribuir indirectamente a través de su entorno para restituirlo al Estado, mejorando su capacidad de gasto y redistribución. 
6. ${ }^{\circ}$ Cabe señalar además que muchas de las investigaciones relacionadas con actividades delictivas vinculadas a la corrupción suelen iniciarse meses o incluso años después de los hechos investigados, lo que evidentemente perjudica la recolección de pruebas y evidencias necesarias para acreditar las responsabilidades en la comisión de un hecho delictivo.

7. ${ }^{\circ}$ Otra complejidad es la localización, mantenimiento y gestión de los efectos que puedan intervenirse procedentes del delito.

El Real Decreto 873/2014, de 10 de octubre, que modifica el Real Decreto 400/2012, de 17 de febrero, desarrolla la estructura orgánica básica del Ministerio del Interior, integrando en un solo órgano al CICO (Centro de Inteligencia Contra el Crimen Organizado) y al CNCA (Centro Nacional de Coordinación Antiterrorista).

La vinculación entre terrorismo y crimen organizado es un hecho objetivo. Para mejorar el intercambio de información entre organismos especializados encargados de analizar la amenaza terrorista y la relacionada con el crimen organizado y extremismo violento, se considera necesario la creación de un nuevo órgano, denominado Centro de Inteligencia contra el Terrorismo y el Crimen Organizado (CITCO), dependiente de la Secretaría de Estado de Seguridad del Ministerio del Interior.

El CITCO impulsará y coordinará la integración y valoración de cuantas informaciones y análisis operativos dispongan las Fuerzas y Cuerpos de Seguridad del Estado en materia de terrorismo, crimen organizado y radicalismo violento para la elaboración de inteligencia criminal estratégica, el establecimiento de criterios de actuación y coordinación operativa entre organismos concurrentes y el diseño de estrategias globales de lucha contra estos fenómenos.

El CITCO, con el apoyo operativo de las Fuerzas y Cuerpos de Seguridad del Estado, ha venido desempeñando funciones de localización de activos procedentes de delitos. No obstante, al no existir órganos especializados en su gestión, una vez decomisados, esos activos quedan a disposición de los órganos jurisdiccionales, que, por lo general, ordenan su recuperación al final del procedimiento, mediante los mecanismos tradicionales de venta por persona especializada o subasta pública. Este mecanismo se ha revelado ineficaz en los procedimientos de mayor complejidad, en la medida en que las necesidades de la gestión de bienes exceden por lo general de las posibilidades materiales de los órganos judiciales.

Estas circunstancias condujeron a reafirmar la necesidad de poner en funcionamiento la Oficina de Recuperación y Gestión de Activos, cuya regulación quedó establecida a través del RD 948/2015, de 23 de octubre.

La Oficina de Recuperación y Gestión de Activos depende del Ministerio de Justicia y se encuentra adscrita a la Secretaría de Estado de Justicia, con rango de Dirección General y según el artículo 2 del referido RD tendrá los siguientes fines:

“a) El apoyo a programas de atención a víctimas del delito, (...).

b) El impulso y dotación de medios de las Oficinas de Asistencia a las Victimas.

c) El apoyo a programas sociales orientados a la prevención del delito y el tratamiento del delincuente.

d) La intensificación y mejora de las actuaciones de prevención, investigación, persecución y represión de los delitos, incluyendo:

1. ${ }^{\circ}$ Los gastos necesarios para la obtención de pruebas en la investigación (...)

2. ${ }^{\circ}$ La adquisición de medios materiales para los órganos competentes en la represión, investigación y realización de las pruebas periciales.

3. ${ }^{\circ}$ La formación y capacitación especializada de los órganos encargados de la prevención y represión de la criminalidad organizada.

4. ${ }^{\circ}$ El reembolso de los gastos en que lícitamente hayan podido incurrir los particulares o los servicios de las Administraciones Públicas que hubiesen colaborado con los órganos competentes en la investigación.

e) La cooperación internacional en la lucha contra las formas graves de criminalidad.

f) La satisfacción de los propios gastos de funcionamiento y gestión de la oficina (...)”.

Como puede observarse, los fines de la ORGA conjugan a la perfección con los objetivos y metas del Desarrollo Sostenible puesto que para su desarrollo no detraen activo alguno de las arcas públicas, facilitando así que los fondos que antaño se utilizaban para los fines anteriormente señalados puedan destinarse a cumplir los objetos y las metas previstos para el año 2030.

En consecuencia, las investigaciones por corrupción son extremadamente complejas ya que deben considerar un amplio grupo de tipos penales, de personas físicas y jurídicas, de realización de análisis de operaciones mercantiles, laborales, bancarias, fiscales, bursátiles, etc., igualmente será necesario recurrir a numerosas fuentes de información, tanto públicas como privadas, algunas con mandamiento judicial, buscando operaciones que muestren indicios de blanqueo y señalen la localización del inmovilizado material obtenido gracias a la acción criminal, además los investigadores actuarán bajo la presión del límite temporal que tienen las investigaciones fiscales en Diligencias de Investigación y las instrucciones judiciales en Diligencias Previas.

\subsection{Investigaciones que requieren especialización}

Este tipo de investigaciones, que hemos identificado como complejas, deben de ser afrontadas por funciona- 
rios especializados puesto que deben de tener amplios conocimientos técnico-jurídicos relacionados con la actividad delictiva investigada y deberán de haber desarrollado habilidades suficientes como para poder emplear medios técnicos que ayuden a la resolución de la investigación.

En la inmensa mayoría de las investigaciones llevadas a cabo, los policías actuantes, deberán de tener un importante conocimiento técnico-jurídico en base a:

a) La normativa que deben de conocer:

- Normativa reguladora de contratos del Sector Público, con todo lo que conlleva, siendo por tanto una faceta difícil de asumir dadas sus propias características.

- Normativa relacionada con el urbanismo, teniendo en cuenta que en determinadas situaciones esta normativa difiere entre localidades, provincias y comunidades autónomas.

- Normativa relacionada con regímenes de tributación y con la Tesorería General de la Seguridad Social o el Instituto Nacional de la Seguridad Social para poder apreciar presuntas comisiones delictivas.

- Normativa relacionada con la prevención del blanqueo de capitales y con la propia actividad delictiva.

b) El conocimiento acerca de la actividad delictiva desarrollada, no solo por los presuntos corruptos, también por los grupos y organizaciones criminales ya que, como ya hemos citado, la corrupción está íntimamente relacionada con el crimen Organizado y como elemento transversas, con el Blanqueo de Capitales.

Cabe señalar que el Plan Estratégico de la Policía Nacional para el periodo 2017-2021 contempla como objetivo estratégico en relación con el crimen organizado en particular y la delincuencia económica en particular, "reducir la capacidad de acción de la delincuencia organizada" mediante "el impulso de las capacidades operativas de la Policía Nacional en materia de investigación patrimonial con el propósito de neutralizar los recursos económicos del crimen organizado". $\mathrm{Y}$ es que el delincuente, el corrupto, necesita blanquear el dinero, esta circunstancia es una necesidad para ellos y en ocasiones, una seria complejidad añadida para la Policía, sin embargo, tomada a tiempo y utilizando la metodología adecuada, puede voltearse y ser utilizada en favor de la investigación puesto que genera nuevas vías indagatorias.

Además, hay que tener en cuenta que en muchas modalidades delictivas la pena se agrava cuando se comete en el seno de una organización o grupo criminal, de ahí que haya que conocer perfectamente el entorno en el que se comete el supuesto delito para, en su caso, demostrar la existencia de una organización o grupo criminal que sustente la supuesta comisión del delito.
También los Policías actuantes deben de tener conocimiento acerca de los medios técnicos necesarios para llevar a cabo este tipo de investigaciones, los funcionarios responsables de estas investigaciones deben de conocer a quién, cuándo y cómo solicitar la información necesaria para evidenciar la presunta comisión del hecho delictivo, del mismo modo, deberán de saber manejar el hardware y el software necesario que le permita analizar la abundante información que manejará en este tipo de investigaciones y poder así llegar a una serie conclusiones objetivas que trasladará a la Autoridad Judicial o al Ministerio Fiscal.

En base a la reciente modificación de la Ley de Enjuiciamiento Criminal, tener la capacidad operativa suficiente para transformarse en agente encubierto informático ${ }^{14}$, requiriendo para ello autorización judicial para actuar en canales cerrados de comunicación o para que a su vez, pueda intercambiar o enviar archivos ilícitos por razón de su contenido en el curso de una investigación se ha vuelto una práctica cada vez más utilizada, entre otros motivos, por los éxitos cosechados.

Esta necesidad de utilizar medios técnicos no se desarrollará de manera exclusiva dentro de una oficina, también será necesario la aplicación de medios técnicos fuera de la misma, exactamente igual que en cualquier otra investigación (vigilancias, dispositivos de seguimientos, identificación de medios de comunicación, ...), pero teniendo en cuenta siempre las especiales características del objetivo perseguido y/o del investigado, tal y como se ha reflejado en puntos anteriores.

\subsection{Investigaciones que requieren formación}

En base al conjunto de características expuestas anteriormente, resulta evidente que los funcionarios que lleven a cabo estas investigaciones deben conjugar dos aspectos complementarios: la formación y la experiencia.

Desde cualquier punto de vista, también desde el policial, la experiencia es también formación y factor clave a la hora de resolver las diferentes problemáticas con las que puede encontrarse un investigador policial en esta tipología delictiva tan concreta. Este factor adquiere un protagonismo absoluto si se tiene en cuenta que no solo se investigarán conductas corruptas, también serán objeto de investigación todas aquellas actividades adicionales, delictivas o no, vinculadas directa o indirectamente, a la corrupción investigada.

Del mismo modo, la formación pura ocupa una posición preeminente dada la naturaleza de las investigaciones a las que se enfrentarán los investigadores. Es una consecuencia lógica de la especialización y es estrictamente necesaria para:

\footnotetext{
4 Ley Orgánica 13/2015, de 5 de octubre, de modificación de la Ley de Enjuiciamiento Criminal para el fortalecimiento de las garantías procesales y la regulación de las medidas de investigación tecnológica.
} 
- Adecuarse al método científico para llevar a cabo sus investigaciones, conforme marca el ciclo de la información: recopilación - evaluación - tratamiento - análisis - difusión.

- Obtener información: fuentes que deben y/o pueden consultarse y las vías para obtener dicha información.

- Saber usar la información: conocer qué información puede ser utilizada y en qué momento, así como qué información debe ser tenida en cuenta tan solo como inteligencia.

- Analizar la información: tal vez sea esta la parte más delicada puesto que habrá de interpretarse correcta y objetivamente la información obtenida, en la mayoría de las cosas con la ayuda de programas o aplicaciones informáticas.

- Establecer conclusiones acordes con la información obtenida, de manera que aclaren las circunstancias objeto de investigación, así como, en caso de ser necesario, solicitar nuevas informaciones complementarias.

Dentro del campo estrictamente económico, aunque vinculado a cualquier actividad criminal, con el objetivo de "marcar las líneas básicas de cualquier investigación patrimonial, concienciar a todos los investigadores policiales de la necesidad de realizar investigaciones patrimoniales simultáneamente con cualquier otra investigación criminal y establecer un método de trabajo unificado", la Comisaría General de Policía Judicial, en febrero del año 2020, publicó un Manual de Investigaciones Patrimoniales que, dada su importancia, debe de formar parte de la formación todo investigador policial.

En este sentido, el cumplimiento del Objetivo de Desarrollo número 4: "Garantizar una educación inclusiva $y$ equitativa de calidad y promover oportunidades de aprendizaje durante toda la vida para todos" no solo permitirá alcanzar una educación de calidad y sostenible, sino que además se convierte en la mejor vacuna y a su vez, en una potentísima herramienta de trabajo para luchar contra la corrupción.

\subsection{La vertiente internacional}

La facilidad que tiene el capital para desplazarse de un país a otro, de un continente a otro, es fruto de la globalización económica y visto el interés que tienen los delincuentes por camuflar el fruto de sus actividades delictivas, es decir, por blanquear su dinero, resulta del todo necesario realizar investigaciones de carácter internacional que ayudan a aflorar los bienes de los que disponen los investigados allende nuestras fronteras.

Estas circunstancias deben de tener su reflejo en la especialización policial, no solo respecto a lo puramente delictivo, sino también en lo que se refiere a la cooperación y coordinación internacional puesto que una de las características de estos grupos criminales es la transnacionalidad.

En la lucha contra la corrupción, tan vinculada al crimen organizado como ya hemos señalado, uno de los objetivos fundamentales se centra en el desmante- lamiento de su estructura de blanqueo, promoviendo la confiscación de sus efectos ${ }^{15}$ y racionalizando la estructura policial investigadora, que deja de tener una dimensión puramente nacional para alcanzar también la internacional.

En su actividad delictiva, los grupos organizados han potenciado el empleo y el aprovechamiento de las nuevas tecnologías, de manera que las redes criminales pueden actuar desde lugares donde puedan sentirse seguras frente a la acción penal o procesal, obteniendo ingentes beneficios económicos que tratan de blanquear y, gracias a un sistema financiero global, canalizar a donde quieran, ya sean paraísos fiscales, ya sean países con una normativa antiblanqueo más laxa, e incluso en países con una supuesta estructura antiblanqueo perfectamente instaurada.

Para asumir esta dimensión internacional, la Policía cuenta con diferentes herramientas, como pueden ser:

\section{a) Los Equipos Conjuntos de Investigación y EUROJUST}

Esta necesidad de mejorar la eficacia de la cooperación internacional no es algo reciente, en 1999, los Estados Miembros de la Unión Europea (UE) se reunieron en Tampere (Finlandia) y se comprometieron a establecer los medios necesarios para la creación de Equipos Conjuntos de Investigación ${ }^{16}$ (ECI) con el fin de luchar contra el tráfico de drogas, la trata de seres humanos y el terrorismo, convirtiéndose así los ECI en el instrumento legal ideal para abordar de una manera eficaz investigaciones penales que tengan carácter internacional, principalmente dentro de la Unión Europea.

Podríamos definir un ECI como un equipo de investigación constituido mediante el acuerdo de las autoridades competentes de dos o más Estados Miembros de la UE para llevar a cabo investigaciones penales en el territorio de alguno o de todos ellos, que requieran una actuación coordinada, con un fin determinado y por un periodo limitado.

En el año 2005 se creó, en el seno de EUROJUST, la Red ECIs y en el año 2011 se dotó a esta Red de su propia Secretaría, a través de la cual se proporciona apoyo para el fomento del uso de los ECI en los Estados Miembros, publicando el Consejo de la Unión Europea, el 14-02-2017 una Guía Práctica de los Equipos Conjuntos de Investigación ${ }^{17}$, elaborada por la Red ECI en cooperación con EUROJUST, EUROPOL y la OLAF ${ }^{18}$.

Por lo que se refiere al apoyo financiero que EUROJUST puede facilitar a los ECI, cabe destacar que esta financiación se ha convertido en una herramienta valiosa para intentar conseguir que las restricciones económicas no hagan decaer el uso de los mismos en la lucha contra los grupos delictivos organizados.

\footnotetext{
Artículo 127 bis del Código Penal.

16 Ley $11 / 2003$, de 21 de mayo, reguladora de los ECI en el ámbito de la Unión Europea y Ley Orgánica 3/2003, de 21 de mayo, complementaria de la Ley reguladora de los ECI, por la que se establece el régimen de responsabilidad penal de los miembros destinados en dichos equipos cuando actúen en España.

17 Consejo de la Unión Europea 6128/1/17 REV 1

18 Oficina Europea de Lucha contra el Fraude de la Comisión Europea.
} 


\section{b) EUROPOL, INTERPOL y SIRENE}

En el Real Decreto 952/2018, de 30 de julio, por el que se desarrolla la estructura básica del Ministerio del Interior, se hace referencia a que la Secretaría de Estado de Seguridad tendrá, entre otras funciones, las reflejadas en el párrafo d), apartado 1 del artículo $2^{\circ}$ : "La dirección y coordinación de la cooperación policial internacional, especialmente con EUROPOL, INTERPOL, SIRENE y los Sistemas de Información de Schengen y los Centros de Cooperación Policial y Aduanera."

Tomando como base el Real Decreto 400/2012, que fue modificado por el ya mencionado 952/2018, sea creó en la Policía Nacional la División de Cooperación Internacional, cuyo contenido se desarrolla en el artículo 11 de la Orden INT/28/2013 y que está compuesta, entre otros por:

- La Oficina Central Nacional de INTERPOL: aporta cooperación técnica y operativa con las policías de otros países y coopera en el auxilio judicial, conforme a lo establecido en los Tratados y Acuerdos Internacionales.

INTERPOL tiene como objetivos la coordinación y asistencia recíproca entre las autoridades de policía, dentro de los límites fijados por las leyes nacionales, y el establecimiento y desarrollo de las instituciones que contribuyan eficazmente a la prevención y represión del derecho común.

A los efectos que nos ocupan, las labores de INTERPOL que podrían ayudarnos en nuestro cometido serían: el intercambio de información sobre delincuencia utilizando un sistema de notificaciones internacionales; el intercambio de información y ayuda a la formación a través de reuniones internacionales; análisis de la información que se aporte a las bases de datos y la tramitación de requerimientos de información.

- La Unidad Nacional de EUROPOL: canaliza y coordina la cooperación técnica y operativa con EUROPOL en el marco de las disposiciones de la UE. Para conseguir su misión EUROPOL divide su actividad en tres áreas:

1. Centro de intercambio de información criminal de la UE. Las capacidades únicas de EUROPOL facilitan el hecho de que pueda constituirse como una plataforma de intercambio de información capaz de facilitar una respuesta operativa eficaz ante las amenazas de seguridad europeas.

2. Principal centro de inteligencia criminal de la UE, maximizando la información disponible y el análisis de la misma, además de cooperar con otros organismos como EUROJUST e INTERPOL.

3. Desarrollar aún más su experiencia policial utilizando nuevas técnicas de investigación y métodos forenses, desarrollando nuevas prácticas analíticas y operativas, asesorando a los Estados miembros, facilitando el intercambio de conocimientos y de formación altamente especializada, siendo en suma el centro de referencia policial europeo.

En el contexto de EUROPOL no hay que olvidar el conocido como ciclo político - EMPACT ${ }^{19}$. En el año 2010 la Unión Europea estableció el primer ciclo político plurianual en la lucha contra la delincuencia organizada y grave de carácter internacional, tratando de desarrollar instrumentos para lograr una cooperación eficaz entre los organismos policiales de los Estados miembros, instituciones de la UE, otras agencias de la Unión y terceros Estados y de esta manera conseguir una respuesta coherente, operativa y sólida sobre las amenazas criminales más urgentes a las que se enfrenta la UE.

El actual ciclo político comprende los años 2017 al $2021^{20}$, identificándose como principales amenazas criminales de la Unión Europea las siguientes:

1. La Ciberdelincuencia.

2. La distribución, el tráfico y la distribución de drogas.

3. El tráfico ilícito de migrantes.

4. La delincuencia organizada contra la propiedad.

5. El tata de seres humanos.

Pero señaló a su vez 3 actividades delictivas transversales a todas ellas, las identifica como "motores del crimen organizado" que permite y facilita la mayoría, sino todas, las formas de delincuencia grave y organizada:

1. El comercio on-line de bienes y servicios ilícitos.

2. El fraude documental.

3. Y el blanqueo de capitales.

- La Oficina SIRENE: facilita la cooperación técnica y operativa establecida en las disposiciones de la UE en el ámbito de la cooperación Schengen.

Debido a la supresión de los controles en la frontera interior y con el objetivo de reforzar y regular, entre otros aspectos, la cooperación policial y judicial, se creó el Sistema de Información Schengen (SIS), que es un sistema informatizado común a todos los países miembros que contiene datos sobre personas y objetos de interés policial y/o judicial, permitiendo que se pueda disponer e intercambiar dicha información por las autoridades competentes de los Estados pertenecientes al SIS. El 09 de abril de 2013, entró en funcionamiento el SIS de nueva generación, el SIS II, que mejora y completa al SIS original e incluye los siguientes datos de interés:

19 EMPACT: European Multidisciplinary Platform against Criminal Threats (Plataforma Multidisciplinar Europea contra las Amenazas Criminales).

20 En: https://www.europol.europa.eu/socta-report 
- Respecto de las personas contiene información de: personas buscadas para su detención a efectos de extradición; personas desaparecidas o amenazadas; personas que deban ser protegidas y las que deban ser objeto de vigilancia o registro; testigos que deban comparecer ante las autoridades judiciales en el marco de un proceso penal; y extranjeros incluidos en la lista de no admisibles por tener prohibida la entrada en territorio Schengen, o por cualquier otra medida de alejamiento, devolución o expulsión.

Se pueden introducir datos biométricos (huellas dactilares y fotografía), se pueden enlazar diferentes descripciones referidas a personas y vehículos y las Órdenes Europeas de Detención y Entrega, se pueden acoplar directamente a las descripciones de las personas buscadas para su detención, entrega o extradición, facilitando que las autoridades competentes velen por su necesario seguimiento.

- Respecto de los objetos, consta información de: los señalados para su incautación, vehículos de motor de cilindrada superior a $50 \mathrm{cc}$, remolques, caravanas, armas de fuego, documentos en blanco, documentos de identidad y billetes de banco que hayan sido sustraídos o robados. También figuran aeronaves, buques, contenedores y medios de pago sustraídos.

\section{c) La red de Consejeros, agregados de Interior y Oficiales de Enlace}

Las Consejerías de Interior son los órganos técnicos de las Misiones Diplomáticas Permanentes del Reino de España, bajo la dirección y coordinación del Jefe de la misma, para el desarrollo de las funciones que, en el marco de las competencias del Ministerio del Interior, se le encomiendan por el RD 1300/2006 ${ }^{21}$ de 10 de noviembre, sobre la organización y funciones de las Consejerías de Interior en las Misiones Diplomáticas de España.

Con carácter general, las Consejerías de Interior apoyarán el ejercicio de las funciones correspondientes al Ministerio del Interior, en el ámbito de sus competencias y entre otras funciones, desempeñarán las siguientes:

a) Colaborar y prestar apoyo a los miembros de las Fuerzas y Cuerpos de Seguridad de otros países.

b) Proporcionar información a los órganos superiores y directivos del Ministerio del Interior y al CITCO (Centro de Inteligencia contra el Terrorismo y el Crimen Organizado) sobre las actividades que desarrollen en materia de lucha contra el terrorismo, el tráfico de drogas y demás expresiones de la criminalidad organizada que afecten a la seguridad interior de España.

c) Servir de enlace con INTERPOL, EUROPOL y demás órganos de cooperación policial internacional, prestando la asistencia precisa para la eje-

Este RD se ha visto modificado parcialmente, en su artículo 5 apartado 6, a través del RD 1894/2008 del 14 de noviembre. cución de comisiones rogatorias internacionales, órdenes de detención, extradiciones y cualquier otra actividad propia de tales organizaciones, sin perjuicio de las reservadas a otros departamentos de la Administración a través de convenios y tratados internacionales.

La Jefatura de las Consejerías será ejercida por el Consejero de Interior sin perjuicio de las funciones de coordinación que corresponden al Jefe de la Misión Diplomática. Los Agregados de Interior dependen del Consejero de Interior, al que asistirán en las funciones que les sean atribuidas por este último. En cuanto a Oficiales de Enlace debemos distinguir entre los Oficiales de Enlace españoles destinados ante los cuerpos policiales extranjeros u otras organizaciones o foros internacionales (INTERPOL, EUROPOL, OLAF, ONU...) y los Oficiales de Enlace pertenecientes a cuerpos policiales de otros países y organismos policiales internacionales destinados en España ante las Fuerzas y Cuerpos de Seguridad del Estado.

\section{d) Otras herramientas:}

- GAFI: el Grupo de Acción Financiera ${ }^{22}$ (GAFI) es el organismo de control mundial de blanqueo de capitales y financiación del terrorismo; establece las normas internacionales que tienen como objetivo prevenir estas actividades ilegales y consecuentemente, el daño que causan a la sociedad. Está formado por más de 200 países y ayuda a las autoridades a perseguir el dinero de los delincuentes, revisando técnicas de blanqueo y fortaleciendo sus estándares para abordar las nuevas amenazas que puedan extenderse.

- RED CARIN ${ }^{23}$ : es una informal de contactos y grupo de cooperación que está compuesta por profesionales de 53 jurisdicciones y 9 organizaciones internacionales, que tiene por objeto ocuparse de todos los aspectos vinculados al comiso de los productos procedentes del delito, estando relacionada a otras redes de recuperación de activos similares del África Austral y América Latina.

- GRUPO EGMONT DE INTELIGENCIA FINANCIERA: su objetivo es colaborar y cooperar con las más de 150 Unidades de Inteligencia Financiera que lo componen, estimulando la lucha internacional contra el blanqueo de dinero y la financiación del terrorismo, especialmente en las áreas de intercambio de información, capacitación y conocimiento.

- Oficinas $\mathrm{ARO}^{24}$ de la Unión Europea: puntos de contacto centrales nacionales que facilitan el rastreo de activos derivados de la delincuencia en toda la UE. La Decisión 2007/845 / JAI del Consejo obligó a los Estados miembros a establecer

22 En: https://www.fatf-gafi.org/

Red Interinstitucional de Recuperación de Activos Camden. En: https://www.carin.network/

24 Asset Recovery Assets. 
tales oficinas y a intercambiar información, tanto previa solicitud como espontáneamente, en las condiciones establecidas en la Decisión Marco 2006/960 / JAI, conocida como "Iniciativa sueca".

En el 2014, el Parlamento Europeo y el Consejo adoptaron la Directiva 2014/42/UE, que establece las normas mínimas para la congelación, gestión y confiscación de activos delictivos, pero además, la adopción del Reglamento (UE) 2018/1805 sobre el reconocimiento mutuo de las órdenes de congelamiento y confiscación ha supuesto un hito en el área de recuperación de activos, facilitando la realización transfronteriza y logrando que la misma sea más rápida y sencilla.

Parece evidente que la motivación de los Estados por tratar de recuperar los efectos del delito, se transfieran donde se transfieran, ocupa un lugar preferente en las políticas de cooperación y coordinación internacional, sin embargo, a pesar de todas las herramientas expuestas anteriormente, lo cierto es que la diversidad de jurisdicciones, aún dentro de la propia Unión Europea, y las voluntades o estrategias políticas en determinados momentos, dificultan, cuando no impiden, el éxito de las iniciativas tomadas en torno a las herramientas enumeradas anteriormente.

\section{Conclusiones}

En base a lo expuesto en el presente artículo podemos establecer las siguientes conclusiones:

1. ${ }^{\circ}$ Resulta imposible establecer un punto de partida, una fecha o acontecimiento histórico a partir del cual pueda hablarse del nacimiento de la corrupción, es una actividad propia del ser humano y de su organización social y podría definirse como una desviación de un poder de actuación, público o privado, en interés particular para conseguir una ventaja patrimonial o de otro tipo, a favor propia o de un tercero.

2. ${ }^{\circ}$ La corrupción no puede observarse desde un punto de vista estanco, no es un hecho o actividad independiente, está íntimamente relacionada con la delincuencia económica en general y con el crimen organizado en particular.

3. ${ }^{\circ}$ La corrupción y las conductas criminales afines se constituyen en una de las principales barreras que se anteponen a la consecución de los objetivos y metas adoptados por la ONU para el 2030 .

4. ${ }^{\circ}$ Si sumamos el coste estimado sobre el PIB español del crimen organizado, del fraude fiscal y de la corrupción en España obtendríamos una cantidad cercana al 10\% del PIB.

5. ${ }^{\circ}$ La actividad delincuencial en general y la corrupción en particular son un buen negocio para el delincuente y los instrumentos básicos con los que cuenta el Estado para combatirla no alcanzan presupuestariamente, en volumen, al supuesto beneficio que consigue el corrupto con su actividad, reduciendo la capacidad del Estado en la generación de presupuestos y más aún, dificultando el compromiso adquirido en el cumplimiento de los Objetivos de Desarrollo Sostenible contenido en la Agenda 2030.

6. ${ }^{\circ}$ La investigación policial en torno a la corrupción y el conjunto de delitos con los que se relaciones se convierte en un elemento fundamental para el Estado y la ciudadanía.

7. ${ }^{\circ}$ Las investigaciones relacionadas con la corrupción son complejas, en base a: la infinidad de delitos que entran en juego, el objeto de la investigación, la persona física o jurídica que se investiga, la alarma social que general, la dificultad de obtener pruebas directas inculpatorias, las circunstancias temporales que sobrevuelan a la propia investigación y la localización, mantenimiento y gestión de los efectos que puedan intervenirse.

8. ${ }^{\circ}$ Las investigaciones relacionadas con la corrupción requieren de una alta especialización por parte de los funcionarios actuantes: amplios conocimientos técnico-jurídicos y de utilización de dispositivos y medios técnicos.

9. ${ }^{\circ}$ Las investigaciones relacionadas con la corrupción requieren de los investigadores una elevada formación que debe conjugar con cierta experiencia operativa.

$10 .^{\circ}$ En la mayoría de las investigaciones relacionadas con la corrupción interviene de manera decisiva la vertiente internacional, lo que exige conocer su funcionamiento.

La labor policial es por tanto una actividad fundamental a la hora de luchar contra la corrupción y los delitos que puedan confluir con ella, facilitando que el Estado pueda contar con fondos que le permitan generar unos presupuestos que faciliten asumir los Objetivos de Desarrollo Sostenible señalados en la Agenda 2030.

A pesar de todas las dificultades señaladas anteriormente, los éxitos policiales en este ámbito se suceden día a día, la especialización y la formación de los policías encargados de estas investigaciones es elevadísima, pero la amenaza es incesante. Sufrimos los efectos más nocivos de la globalización que afectan a la seguridad y la estabilidad de España, de la Unión Europea y del conjunto de la comunidad internacional, de ahí que se requiere una respuesta eficaz de las Fuerzas y Cuerpos de la Seguridad del Estado, las cuales tienen el firme compromiso de luchar contra la corrupción, compromiso ineludible con la seguridad de todos los españoles, con la economía nacional y con los Objetivos de Desarrollo Sostenible que permitirán un desarrollo económico, medioambiental y social, seguro y sostenible. 


\section{Documentos y normativa}

Decisión 2007/845/JAI del Consejo, de 6 de diciembre de 2007, sobre cooperación entre los organismos de recuperación de activos de los Estados miembros en el ámbito del seguimiento y la identificación de productos del delito o de otros bienes relacionados con el delito.

Decisión marco 2006/960/JAI del Consejo, de 18 de diciembre de 2006, sobre la simplificación del intercambio de información e inteligencia entre los servicios de seguridad de los Estados miembros de la Unión Europea.

Directiva 2014/42/UE del Parlamento Europeo y del Consejo, de 3 de abril de 2014, sobre el embargo y el decomiso de los instrumentos y del producto del delito en la Unión Europea.

Greenpace y el Observatorio de la Sostenibilidad. Informe "A Toda Costa", 24-07-2018.

Guía Práctica de los Equipos conjuntos de investigación, Consejo de la Unión Europea 6128/1/17 REV 1.

Manual de Investigaciones Patrimoniales de la Comisaría General de Policía Judicial, Policía Nacional.

Ley 11/2003, de 21 de mayo, reguladora de los Equipos Conjuntos de Investigación penal en el ámbito de la Unión Europea

Ley Orgánica 10/1995, de 23 de noviembre, del Código Penal.

Ley Orgánica 3/2003, de 21 de mayo, complementaria de la Ley reguladora de los ECI, por la que se establece el régimen de responsabilidad penal de los miembros destinados en dichos equipos cuando actúen en España.

Plan Estratégico de la Policia Nacional 2017-2021.

Resolución 58/4 de la Asamblea General de la ONU, de 31 de octubre de 2003 por la que se aprueba la Convención de las Naciones Unidas contra la Corrupción.

Real Decreto de 14 de septiembre de 1882 por el que se aprueba la Ley de Enjuiciamiento Criminal.

Real Decreto 1300/2006, de 10 de noviembre, sobre organización y funciones de las Consejerías de Interior en las Misiones Diplomáticas de España.

Real Decreto 873/2014, de 10 de octubre, por el que se modifica el Real Decreto 400/2012, de 17 de febrero, por el que se desarrolla la estructura orgánica básica del Ministerio del Interior.

Real Decreto 948/2015, de 23 de octubre, por el que se regula la Oficina de Recuperación y Gestión de Activos.

Real Decreto 952/2018, de 27 de julio, por el que se desarrolla la estructura orgánica básica del Ministerio del Interior.

Reglamento (UE) 2018/1805 del Parlamento Europeo y del Consejo, de 14 de noviembre de 2018, sobre el reconocimiento mutuo de las resoluciones de embargo y decomiso.

Transparencia Internacional, Informe global IPC 2019, enero 2020.

United Nations office on Drugs and Crime, Annual Report 2014.

\section{Bibliografía}

Barlett Quintanilla, P., Cummins-Tripodi, P., Marié, A., y Mussio, E. (2020). The costs of corruption across the EU. The Greens/ EFA in the European Parlament.

León, C., De León, J., y Araña, J. E. (2014). "Relación entre corrupción y satisfacción”, Revista de Economía Aplicada, 22 (64): 31-58.

López González, S. P. (2018). "La política es una cuestión de buenos ciudadanos”, Derecho Global. Estudios sobre Derecho y Justicia, 3 (9): 9-10

Pulido, A., y Pérez, J. (2017). "Incertidumbres de futuro de la economía española", en Consejo General de Economistas, Madrid: Economistas Consejo General, pp. 1-74.

Rasillo López, P. (2016). “Los delitos de corrupción tras la reforma del Código Penal por LO 1/2015”, Elderecho.com. En: https:// elderecho.com/los-delitos-de-corrupcion-tras-la-reforma-del-codigo-penal-por-lo-12015

Sutherland, E. H. (1983). White collar crime. New Haven: Yale University Press.

Tarancón Huarte, N. (2016). "Maat encadenada: La corrupción en Egipto durante el Reino Nuevo”, Anesteria, 5: 15-24. 